\title{
The Diagnostic Value of Leukocyte Esterase Reagent Dip- stick in Spontaneous Bacterial Peritonitis Diagnosis in Patients with Liver Cirrhosis
}

\author{
Amal Gad ${ }^{\prime *}$, Nader el Nemr², Mohamed Saad ${ }^{3}$
}

${ }^{1}$ Department of: Internal Medicine, Faculty of Medicine, Suez Canal University, ${ }^{2}$ Department of Endemic and Infectious Diseases, Faculty of Medicine, Suez Canal University, ${ }^{3}$ Department of Internal Medicine, Ismailia General Hospital, Ismailia, Egypt

\begin{abstract}
Background: Spontaneous bacterial peritonitis (SBP) is a serious complication of advanced liver cirrhosis which requires rapid diagnosis for the initiation of proper antibiotic therapy. Manual examination of ascetic fluid is a rather time-consuming procedure. The leukocyte esterase (LE) reagent dipstick is based on the esterase activity of activated granulocytes which reacts with an ester-releasing hydroxyphenylpyrrole causing a color change in the azo dye of reagent strip. Aim: the aim of this study was to evaluate the diagnostic value of leukocyte esterase reagent dipstick in SBP diagnosis in patients with liver cirrhosis attending Suez Canal University Hospital. Methods: ascetic fluid cell count using the counting chamber method was compared to Leucocyte Esterase strip rapid test in two groups of patients (65 ABP vs 65 non-SBP). The strips were read in 120 seconds using colorimetric 5-grade scale (from 0 to 4 ). The grades (0-2) were considered a negative test while grades (3-4) were considered a positive one. Results: Comparison of the SBP +ve and -ve groups showed a sensitivity of LE strips of $(82 \%)$ with a high specificity (94\%), PPV (93\%) and NPV (84\%) for the diagnosis of SBP. A good correlation between the LE strip color grade and the ascetic fluid PMNL cell count number $(P<0.05)$ Conclusion: the leukocyte esterase reagent dipstick test is a rather specific, rapid, inexpensive and simple bedside method for diagnosis of SBP method for. A negative LE test result excludes SBP with a high accuracy.
\end{abstract}

Keywords: Leukocyte Esterase, Spontaneous Bacterial Peritonitis, Liver Cirrhosis

\section{Introduction}

Spontaneous bacterial peritonitis is defined as an infection of the ascetic fluid in the absence of a contiguous source of infection and/or an intra-abdominal inflammatory focus. Depending on the examined patient population (outpatients or hospitalized), the prevalence of SBP varies from $3.5 \%$ and $30 \%$. Around $50 \%$ of SBP episodes are present at the time of hospital admission, whilst the remainders are acquired during the hospitalization period ${ }^{(1)}$. The mortality of untreated SBP remains high (> 80\%), and a satisfactory patient course and clinical outcome is based on an aggressive approach aiming to rapid diagnosis and prompt initiation of antibiotic 
therapy ${ }^{(2)}$. An ascetic fluid polymorph nuclear (PMN) leukocyte count $\geq 250 / \mathrm{mm} 3$, irrespective of the ascetic fluid culture result, is universally accepted nowadays as the best surrogate marker for diagnosing SBP. The presence of positive ascetic fluid cultures is confirmatory, but by no means a necessary prerequisite for instigation of antibiotic therapy. In fact, it is considered a "fatal" mistake to wait $48 \mathrm{~h}$ for culture results before initiating therapy, where it is indicated (3). Manual ascetic fluid PMN counting is laborious and costly. Therefore, any alternative test that may provide or, more importantly, exclude a diagnosis of SBP at the bedside and reduce the "tap-to-first shot" time is considered welcome $^{(4)}$. The leukocyte esterase reagent strips (LERS), is commonly used in everyday practice for the rapid diagnosis of urinary tract infections (UTIs), LERS had already been successfully evaluated in the diagnosis of infection in other sterile body fluids i.e. synovial, pleural, cerebrospinal fluid and peritoneal dialysate ${ }^{(5)}$. The LERS test is based on the esterase activity of the leucocytes. A pyrrole, esterified with an amino-acid is used as the substrate; hydrolysis of the ester (mediated by the esterase) releases the pyrrole which in turn reacts with a diazonium salt yielding a violet or purple azo dye in the relevant pad of the strip ${ }^{(6)}$ LERS are not specific for PMNs and the interpretation of the colorimetric reaction is inherently subjective, therefore the method is considered qualitative or semi-quantitative at best. Butani et al were the first to present their results on the use of LERS in SBP diagnosis(7) .Then, various LERS were eventually validated while the grading system is different for each dipstick, and therefore the cut-off leucocyte count should be used instead, in order to draw meaningful conclusions $^{(8)}$. Two systematic reviews ${ }^{(9-10)}$ have been published in 2008 , both pointing out that the heterogeneity in the number of patients included in each study, the ascetic fluid samples tested and the SBP episodes observed did not allow pooling of the results via meta-analysis. Overall, the Aution ${ }^{\circledR}$ and Combur ${ }^{\circledR}$ dipsticks have performed better (regarding the negative predictive value) than the Multistix ${ }^{\circledR}$. The spectrophotometric analyzer Clinitek ${ }^{\circledR}$ 50, compatible with the Multistix ${ }^{\circledR}$ dipstick, was used in only 6 studies ${ }^{(11)}$. The rather intense research on the field has brought up important details on the limitations of LERS. First, the results seem to be influenced by the number of PMNs in the ASITIC FLUID, LERS performing less well if the PMN count $<1000 / \mu \mathrm{L}^{(12)}$. Second, all LERS validated in the SBP studies were initially designed for use in the diagnosis of UTIs; in infected urine though, both the number of leucocytes and the protein content are quite different, the first being significantly higher than in most SBP(12) while the latter does not exceed the $1 \mathrm{~g} / \mathrm{L}$ level. The above 2 factors are considered significant for the observed low sensitivity of some LERS but aside the fact that there is significant inter-study variability in terms of the LERS brands used, as well as to the cut-off level examined. LERS are not specific for PMNs and the interchangeable use of PMNs and leucocytes (seen in the majority of the studies) is confusing to the reader. Finally, LERS are not suitable for the few cases of chylous ascites or peritoneal tuberculo$\mathrm{sis}^{(13)}$. On the other hand, LERS have consistently given a high negative predictive value (NPV) of above $95 \%$ in the majority of the studies and, as in SBP, a false positive result (which might eventually lead to the 'adverse' administration of a single dose of an overall well-tolerated antibiotic is considered ethically and medically acceptable advocating the use of LERS as a preliminary screening tool for SBP diagno$\mathrm{sis}^{(12)}$. In addition, Castelote et al showed that LERS, despite their qualitative nature, 
could be well used in the clinical management of SBP. The low cost of the strips can be considered a significant advantage (14). The aim of this study was to assess the usefulness of using leukocyte esterase reagent strips for the diagnosis of spontaneous bacterial peritonitis (SBP) in patients with liver cirrhosis associated with ascites attending Suez Canal University Hospital.

\section{Patients and Methods}

Design: Cross-sectional analytic study.

Setting of the study: Inpatient wards of Internal Medicine Department and Emergency ward Suez Canal University Hospital.

Target population \& sampling: All patients with liver cirrhosis associated with ascites were enrolled according to clinical, laboratory and ultra sonographic criteria regardless the presence or absence of clinical evidence of SBP.

Inclusion criteria: Patients with liver cirrhosis, age above 18 years old, both genders were involved. Exclusion criteria: Patients with liver metastasis and hepatocellular carcinoma. Patients with ascites due to other cause (malignant, cardiac, renal, pancreatic and tuberculous). Patients with evidence of secondary bacterial peritonitis. Recent abdominal surgical intervention. Antibiotic administration in last 2 weeks.

Study Methods: Patients were divided into 2 groups: i) SBP + ve patients with cirrhosis evident by PMN cell count in ascetic fluid $\geq 250 / \mathrm{mm}^{3(15)}$. ii) SBP -ve patients with cirrhotic with ascetic fluid PMN count $<250$ cells $/ \mathrm{mm}^{3}$.

Data collection: Through the following: i) Full medical history. ii) Medical examination: (general, chest, abdominal examination). iii) Laboratory investigations: Alanine transaminase
(ALT), Aspartate transaminase (AST), S. Albumin, S. Bilirubin (Total and Direct), prothrombin time and INR. Complete blood picture. Random blood sugar and $S$. creatinine. Diagnostic paracentesis: Immediately after ascetic fluid paracentesis; the ascetic fluid was tested by the leukocyte esterase reagent strips using the Multistix ${ }^{\circledR}$ dipstick $^{(11)}$ designed for testing urine for leukocytes. The strips were read in 120 seconds using colorimetric 5 -grade scale (from 0 to 4 ). A correlation between $\mathrm{PMN}$ and the 5-grade scale was suggested by the manufacturer as follows: grade $0=0 \mathrm{PMN} / \mathrm{ml}$; grade $1=15 \mathrm{PMN} / \mathrm{ml}$; grade $2=70$ $\mathrm{PMN} / \mathrm{ml}$; grade $3=125 \mathrm{PMN} / \mathrm{ml}$; and grade $4=500 \mathrm{PMN} / \mathrm{ml}$. The grades (02) were considered a negative test while grades (3-4) were considered a positive test. Ascetic fluid was also checked for cytology, PMN leukocyte and lymphocyte count, glucose, protein and LDH).

\section{Results}

This study was a cross-sectional analytical study, 130 participants were enrolled. They were categorized into two equal groups (65 SBP +ve and -ve patient in each). The results showed no statistically significant difference between the two study groups in their background characteristics Table (1). With regards to the etiology of liver disease; HCV was higher in the +ve SBP when compared to the -ve SBP group; however, the difference was not statistically significant even for either causes, duration of liver disease or child's $C$ distribution among the two groups. ( $P$ > 0.05). Table (2). There was no statistically significant difference between the two groups in terms of ascetic fluid analysis parameters other than the total PNL count $(p>0.05)$. The ascetic PNL count 
was significantly higher in the SBP group compared to non- SBP (1297 \pm 685 vs. 224 $\pm 73, \mathrm{p}<0.001$ ) Table (4). The results of the dipstick testing in each group demonstrated a significant difference as 53 (82\%) patients in the SBP group showed positive test (grade 3-4) compared with only 4 (6 $\%)$ in the non SBP. Twelve (18\%) patients in SBP group showed negative test (grades
$0,1,2)$ compared to 61 (94\%) patients in the non SBP, Table (5). Thus, dipstick testing grades 3 and 4 are highly sensitive ( 82 $\%)$ for the diagnosis of ascetic fluid infection with a high specificity (94\%) PPV (93 $\%$ ) and NPV (84\%) Table (6). The validity of different grades of leukocyte esterase test in the diagnosis of SBP was shown in figure 1 that showed the ROC curve.

Table 1: Comparison between the two study groups in terms of socio-demographic characteristics

\begin{tabular}{|c|c|c|c|c|}
\hline \multicolumn{2}{|l|}{ Variable } & $\begin{array}{c}\text { SBP +ve } \\
(n=65) \\
n(\%)\end{array}$ & $\begin{array}{c}\text { SBP -ve } \\
(n=65) \\
n(\%)\end{array}$ & $\mathrm{p}$ value \\
\hline \multirow[t]{2}{*}{ Age } & $\begin{array}{l}\leq 50 y \\
>50 y\end{array}$ & $\begin{array}{l}17(26.2) \\
48(73.8)\end{array}$ & $\begin{array}{l}19(29.2) \\
46(70.8)\end{array}$ & 0.33 \\
\hline & Mean \pm SD & $54.7 \pm 6.2$ & $56.3 \pm 10$ & 0.69 \\
\hline Gender & Male & $23(35.4)$ & $32(49.2)$ & 0.11 \\
\hline Residence & Rural & $42(64.6)$ & $41(63.1)$ & 0.85 \\
\hline Occupation & Not working & $62(95.4)$ & $49(75.4)$ & 0.21 \\
\hline Marital status & Not married & $7(10.8)$ & 0 & 0.27 \\
\hline Education & Illiterate & $33(50.8)$ & $39(60.0)$ & 0.56 \\
\hline
\end{tabular}

Table 2: Comparison between the study groups in terms of the background liver disease

\begin{tabular}{|l|c|c|c|}
\hline \multirow{2}{*}{ Variable } & SBP $+v e(n=65)$ & SBP -ve $(\mathrm{n}=65)$ & p value \\
\cline { 2 - 4 } & $\mathrm{N}(\%)$ & $\mathrm{N}(\%)$ & \\
\hline Etiology & & & \\
HCV & $45(69.2)$ & $49(75.3)$ & \\
Bilharzial & $13(20.0)$ & $12(18.5)$ & 0.33 \\
HBV & $2(3.0)$ & $\begin{array}{c}1(1.5) \\
3(4.6)\end{array}$ & \\
Unknown & $5(7.6)$ & $6.72 \pm 3.4$ & 0.459 \\
\hline Duration of liver disease & $9.12 \pm 4.9$ & $59(90.8)$ & 0.082 \\
Mean \pm SD & $52(80.0)$ & \\
\hline Child's C & &
\end{tabular}

\section{Discussion}

The aim of this study was to evaluate the diagnostic validity of leukocyte esterase reagent dipstick in rapid diagnosis of SBP in patients with liver cirrhosis associated with ascites to improve the outcome of this lethal infection and to decrease mortality in this group of patients. The most common etiology of the liver disease in our study population was HCV (72.31\%) then bilharziasis (19.25\%) with no statistically significant difference between both groups. The test used in our study is based on the esterase activity released from granulocytes present in the ascetic fluid that reacts with an esterified chemical compound (derivatized pyrrole amino acid ester) in the reagent strip. Hydrolysis of this ester by esterase release 3-Hydroxy 
-5-phenyl-pyrrol which in turn reacts with a diazonium salt (in the reagent strip) to yield a violet azo dye, the intensity of which correlates to leukocyte count ${ }^{(16)}$.

Table 3: Co-morbidities associated with liver disease in both study groups

\begin{tabular}{|l|c|c|c|}
\hline \multirow{2}{*}{ Variable } & SBP $+v e(n=65)$ & SBP -ve $(n=65)$ & p value \\
\cline { 2 - 3 } & $\mathrm{N}(\%)$ & $\mathrm{N}(\%)$ & \\
\hline No co-morbidity & $46(70.8)$ & $41(63.1)$ & \\
\hline DM & $16(24.6)$ & $14(21.5)$ & \multirow{2}{*}{0.49} \\
\hline Renal Disease & $3(4.6)$ & 0 & \\
\hline HTN & 0 & $5(7.7)$ & \\
\hline Cardiac Disease & 0 & $5(7.7)$ & \\
\hline
\end{tabular}

Table 4: Ascetic fluid analysis in both study groups

\begin{tabular}{|l|c|c|c|}
\hline Variable & SBP $+v e ~(n=65)$ & SBP -ve $(\mathrm{n}=65)$ & P Value \\
\hline Ascetic protein $(\mathrm{gm} / \mathrm{dl})$ & $1.77 \pm 0.66$ & $2.12 \pm 1.17$ & $>0.05$ \\
\hline Ascetic $\mathrm{LDH}(\mathrm{mg} / \mathrm{dl})$ & $157.9 \pm 81.8$ & $101.3 \pm 32.7$ & $>0.05$ \\
\hline Ascetic glucose $(\mathrm{mg} / \mathrm{dl})$ & $146.0 \pm 78.4$ & $119.2 \pm 27.7$ & $>0.05$ \\
\hline Ascetic count $(\mathrm{PMN} / \mathrm{ml})$ & $1297.1 \pm 685.3$ & $224.1 \pm 73.9$ & 0.000 \\
\hline Ascetic albumin $(\mathrm{gm} / \mathrm{dl})$ & $0.21 \pm 0.11$ & $0.36 \pm 0.2$ & $>0.05$ \\
\hline SAAG* & $2.09 \pm 0.4$ & $2.02 \pm 0.3$ & $>0.0599$ \\
\hline
\end{tabular}

* SAAG $=$ serum/ascetic albumin gradient; Data are presented as mean \pm SD

Table 5: Results of the dipstick testing of both study groups

\begin{tabular}{|c|c|c|c|}
\hline & Variable & SBP +ve $(\mathrm{n}=65)$ & SBP -ve $(\mathrm{n}=65)$ \\
\hline \multirow{2}{*}{$\begin{array}{c}\text { Negative } \\
\text { test }\end{array}$} & Dipstick 0 & $1(1.53 \%)$ & $52(80 \%)$ \\
\cline { 2 - 4 } & Dipstick 1 & $2(3.08 \%)$ & $6(9.23 \%)$ \\
\cline { 2 - 4 } & Dipstick 2 & $9(13.85 \%)$ & $3(4.63 \%)$ \\
\hline \multirow{2}{*}{$\begin{array}{c}\text { Positive } \\
\text { test }\end{array}$} & Dipstick 3 & $22(33.85 \%)$ & $2(3.08 \%)$ \\
\cline { 2 - 4 } Total & Dipstick 4 & $31(47.69 \%)$ & $2(3.08 \%)$ \\
\hline
\end{tabular}

Dipstick testing grade 0-2 were considered negative while grade 3-4 were considered positive

The study revealed that at a threshold of $250 \mathrm{PMNL} / \mathrm{mm} 3$ (grade 3 ) in ascetic fluid; LE test is a rather sensitive ( $82 \%$ ) and specific (94\%) with a high NPV value, that makes it a useful bedside screening tool, especially in the ambulatory setting such as outpatient clinics or in the emergency room. In other words; in patients with negative LE test; SBP can be ruled out with a high degree of certainty. Conversely, the satisfactory PPV of these strips substantiates the immediate start of appropriate antibiotic therapy in cases of positive testing, without any delay. Our results are similar to other three studies evaluating the use of reagent strips in the diagnosis of SBP. In one study 90 ascetic fluid samples were tested. Sensitivity and PPV were $89 \%$, specificity and NPV were $99 \%$, and only one false negative was reported ${ }^{(17)}$. Vanbiervliet et al. published the first study on the use of LER strip test in 
ascetic fluid. They tested 72 consecutive patients with liver cirrhosis using Multistix 8 SG strips, the most frequently used urinary reagent strip in France. They found $100 \%$ sensitivity and specificity of this test for the diagnosis of SBP. Since then, studies from different parts of the world have confirmed these results. The sensitivity of urinary reagent strips in these studies for the diagnosis of SBP has ranged between $85 \%$ and $100 \%$, with specificity between $98 \%$ and $100 \%{ }^{(18-24)}$. Sapey et al. showed that different brands can achieve different accuracy in the diagnosis of SBP (25).

Table 6: Sensitivity, Specificity, Positive and negative predictive values of dipstick testing

\begin{tabular}{|l|c|c|}
\hline Variable & & Value \\
\hline Sensitivity & & $82 \%$ \\
\hline Specificity & & $94 \%$ \\
\hline Positive Predictive Value & & $93 \%$ \\
\hline Negative Predictive Value & & $84 \%$ \\
\hline
\end{tabular}

Dipstick testing grade $0-2$ were considered negative while grade 3-4 were considered positive

In Egypt a study showed a sensitivity of $92 \%$, and specificity of $88 \%$ with positive predictive value of $88 \%$ using urine testing strips (Uristik) with a 4 grade colorimetric scale $(0-3)^{(26)}$. Hence, such a discrepancy among studies would justify further studies to determine the best reagent strip brand that should be used for the prompt SBP diagnosis. In view of our results and those of others we believe that there is great potential is using leukocyte esterase reagent strips in the diagnosis of SBP. Their particularly high NPV could make them a useful bedside screening tool, especially in an ambulatory setting such as an outpatient paracentesis clinic or in the emergency room. Patients with negative testing could be quickly discharged and readmitted in the rare instance that cytology informed the diagnosis. Conversely, the satisfactory PPV of these strips substantiates the immediate start of appropriate antibiotic therapy in cases of positive testing, in any setting. In some small hospitals with limited laboratory facilities,
PMN counts in ascetic fluid cannot be performed on an emergency basis (at night or on weekends). Thus, the use of this diagnostic modality could save lives by prompting early therapy. The limitations of the strip test include absence of a cut-off corresponding to cell count of 250 $\mathrm{PMNL} / \mathrm{mL}$ in the reagent strip, and the possibility of inter-observer variation in matching of color. Thus, it may be useful to confirm grade 3 color changes with cell count. Further, it may be possible to manufacture modified test strips specifically for the diagnosis of SBP, such that color change corresponds to a cut-off for 250 $\mathrm{PMNL} / \mathrm{mL}$ of fluid. Also, these data will require confirmation in larger groups of patients. The use of automation in reading the reagent strip ${ }^{(27)}$ and in the cell (28) may eliminate human error and improve test performance. Last, it may not be unreasonable to consider initiating research and development of a leukocyte reagent strip specifically adapted to the detection of PMN in ascites. 


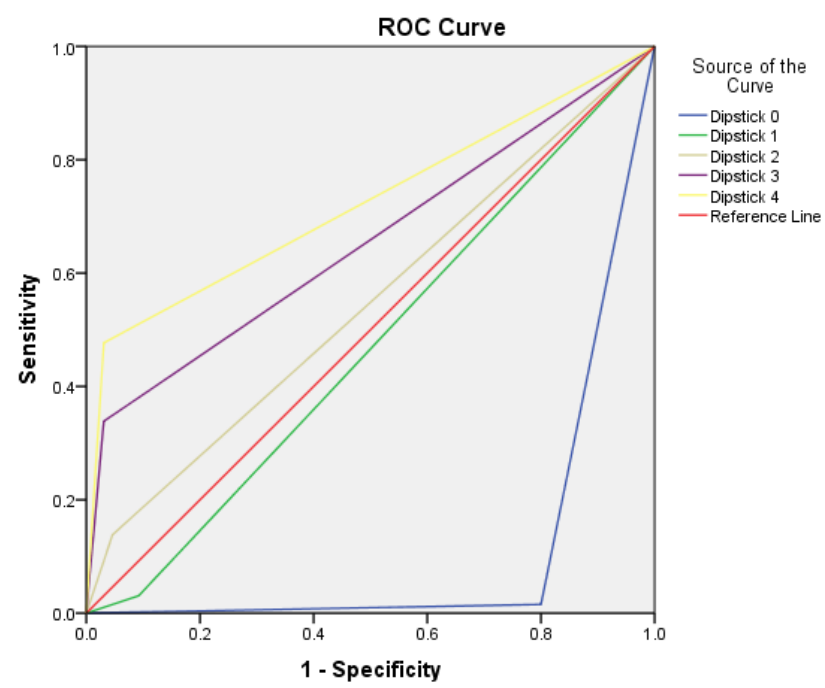

Area Under the Curve

\begin{tabular}{|c|c|c|c|c|c|}
\hline \multirow{2}{*}{$\begin{array}{c}\text { Test Result } \\
\text { Variable(s) }\end{array}$} & \multirow{2}{*}{ Area } & \multirow{2}{*}{$\begin{array}{c}\text { Std. } \\
\text { Error }\end{array}$} & \multirow{2}{*}{$\begin{array}{c}\text { Asymptotic } \\
\text { Sig }\end{array}$} & \multicolumn{2}{|c|}{$\begin{array}{c}\text { Asymptotic } 95 \% \text { Confidence } \\
\text { Interval }\end{array}$} \\
\cline { 5 - 6 } & & & & Lower Bound & Upper Bound \\
\hline Dipstick 0 & .108 & .032 & $<0.001$ & .046 & .169 \\
\hline Dipstick 1 & .469 & .051 & .545 & .370 & .569 \\
\hline Dipstick 2 & .546 & .051 & .364 & .447 & .645 \\
\hline Dipstick 3 & .654 & .048 & .002 & .559 & .749 \\
\hline Dipstick 4 & .723 & .045 & $<0.001$ & .634 & .812 \\
\hline
\end{tabular}

Figure 1: Validity of different grades of leukocyte esterase test in the diagnosis of SBP

\section{References}

1. Wiest R, Krag A, and Gerbes A. Spontaneous bacterial peritonitis: recent guidelines and beyond. Gut 2012; 61(2):297-310.

2. Dever JB, and Sheikh MY. Review article: spontaneous bacterial peritonitis-bacteriology, diagnosis, treatment, risk factors and prevention. Alimentary Pharmacol Therapeutics 2015; 41(11):11161131.

3. Rerknimitr R, Limmathurotsakul D, Bhokaisawan $\mathrm{N}$, et al. A comparison of diagnostic efficacies among different reagent strips and automated cell count in spontaneous bacterial peritonitis. J Gastroenterol Hepatol 2010; 25(5): 946950.

4. Vanbiervliet G, Rakotoarisoa C, Filippi et al. Diagnostic accuracy of a rapid urinescreening test (Multistix8SG) in cirrhotic patients with spontaneous bacterial peritonitis. Euro J Gastroenterol Hepatol
2002; 14(11): 1257-1260.

5. Koulaouzidis A, Bhat S. and Saeed AA. Spontaneous bacterial peritonitis. WJG 2009; 15 (9): 1042-1049.

6. Téllez-Ávila FI, Chávez-Tapia NC, FrancoGuzmán AM, et al. Rapid diagnosis of spontaneous bacterial peritonitis using leukocyte esterase reagent strips in Emergency Department: Uri-Quick Clini$10 S G \AA$ vs. Multistix $10 \mathrm{SG}{ }^{\circledR}$. Ann Hepatol 2012; 11(5): 696-699.

7. Butani RC, Shaffer RT, Szyjkowski RD, et al. Use of Multistix ${ }^{\circledR}$ leukocyte esterase dipstick testing for ascetic fluid infection. Gastroenterology 2000; 118(4): A979.

8. Nousbaum J. Cadranel JF, Nahon P, et al. Diagnostic accuracy of the Multistix 8 SC reagent strip in diagnosis of spontaneous bacterial peritonitis. Hepatology 2007; 45(5): 1275-1281.

9. Koulaouzidis A, Leontiad G, Abdullah $M$, et al. Leucocyte esterase reagent strips for the diagnosis of spontaneous bacterial peritonitis: a systematic review. 
Euro J Gastroenterol Hepatol 2008; 20(11): 1055-1060.

10. Nguyen-Khac E, Cadranel JF, Thevenot T, et al. Review article: the utility of reagent strips in the diagnosis of infected ascites in cirrhotic patients. Alimentary Pharmacol Therapeutics 2008; 28(3): 282-288.

11. Castellote J, and Xiol X. Reagent strips and spontaneous bacterial peritonitis. Alimentary Pharmacol Therapeutics 2008; 28(5): 660.

12. Nousbaum J-B, and Cadranel J-F. [Are reagent strips useful for the diagnosis of spontaneous bacterial peritonitis?]. Gastroenterologie clinique et biologique 2006; 30(3):439-441.

13. Gulberg V, Gerbes AL, Sauerbruch T, et al. Insufficient sensitivity of reagent strips for spontaneous bacterial peritonitis. Hepatology 2007;46(5): 1669.

14. Castellote J, Girbau A, Ariza X, et al. Usefulness of reagent strips for checking cure in spontaneous bacterial peritonitis asitic fluidter short-course treatment. Alimentary Pharmacol Therapeutics 2010; 31(1): 125-130.

15. Ginès $P$, Angeli $P$, Lenz $K$, et al. EASL clinical practice guidelines on the management of ascites, spontaneous bacterial peritonitis, and hepatorenal syndrome in cirrhosis. J Hepatol 2010; 53(3): 397-417.

16. Kutter D, Figueiredo G, Klemmer L. Chemical detection of leukocytes in urine by means of a new multiple test strip. J Clin Chem Clin Biochem.1987; 25(2):91-94.

17. Butani RC, Shaffer RT, Szyjkowski RD, et al. Use of Multistix ${ }^{\circledR}$ leukocyte esterase dipstick testing for ascetic fluid infection. Gastroenterology 2000; 118(4): A979.

18. Thevenot T, Cadranel JF, Nguyen-Khac E, et al. Diagnosis of spontaneous bacterial peritonitis in cirrhotic patients by use of two reagent strips. Euro J gastroenterol \& hepatol 2004; 16(6): 579-583.

19. Farmer AD, Cook MJ, Bruckner Holt CE, et al. Leucocyte esterase reagent strips for the diagnosis of spontaneous bacterial peritonitis: a systematic review Euro J Gastroenterol Hepatol 2009; 21(9):
1102.

20. Sam R, Sahani $M$, Ulozas E, et al. Utility of a peritoneal dialysis leuokocyte strip in diagnosis of peritonitis. Artif Organs 2002; 26: 546-548.

21. Wisniewski B, Rautou PE, Al Sirafi Y, et al. Diagnosis of spontaneous ascites infection in patients with cirrhosis: reagent strips. Presse medicale 2005; 34(14): 997-1000.

22. Sarwar S, Alam A, Izhar M, et al. Bedside diagnosis of spontaneous bacterial peritonitis using reagent strips. J College of Physicians and Surgeons--Pakistan 2005; 15(7): 418-421.

23. Kim DY, Kim JH, Chon CY, et al.,. Usefulness of urine strip test in the rapid diagnosis of spontaneous bacterial peritonitis. Liver international, 25 (6), pp.1197-1201.

24. - Mendler MH, Agarwal A, Trimzi M, et al; 2010. A new highly sensitive point of care screen for spontaneous bacterial peritonitis using the leukocyte esterase method. J Hepatol, 53(3), pp.477-483.

25. Sapey T, Kabissa D, Fort E, et al., 2005. Instant diagnosis of spontaneous bacterial peritonitis using leukocyte esterase reagent strips: Nephur-Test vs. MultistixSG. Liver international, 25(2), pp.343-348.

26. Talaat A \& Mohamed M. Leucocyte esterase dipstick in diagnosis and followup of spontaneous bacterial peritonitis. Egy Liver J 2011, 1(3), pp.102-106.

27. Zaman Z, Roggeman S, Verhaegen J. Unsatisfactory performance of flow cytometer UF-100 and urine strip in predicting outcome of urine cultures. J. Clin. Microbiol. 2001, 39: 4169-4171.

28. Angeloni S. Nicolini $G$, Merli $M$, et al., 2003. Validation of automated blood cell counter for the determination of polymorphonuclear cell count in the ascetic fluid of cirrhotic patients with or without spontaneous bacterial peritonitis. Am J Gastroenterol, 98(8), pp.18441848. 